\title{
PAJÉ, CONHECIMENTO CULTURAL E TERMINOLOGIA DE PLANTAS MEDICINAIS EM PARKATÊJÊ
}

JAQUELINE DE ANDRADE REIS ${ }^{1}$

$U F P A$

MARÍLIA DE NAZARÉ DE OLIVEIRA FERREIRA ${ }^{2}$

$U F P A$

\begin{abstract}
RESUMO: $O$ presente artigo consiste no estudo da terminologia de plantas medicinais utilizadas na produção de remédios para o tratamento e a cura de doenças pelos Parkatêjê, comunidade localizada na Terra Indígena Mãe Maria, no município Bom Jesus do Tocantins, no sudeste do estado do Pará. O resultado prático do trabalho foi a elaboração de um glossário terminológico de plantas medicinais que emergem do discurso do pajé, considerado um especialista em saúde indígena, conforme Athias (2015). O estudo ancora-se nos pressupostos teóricos e metodológicos da Socioterminologia (FAULSTICH, 1990, 1995, 2006, 2010a e 2010b; GAUDIN, 1993) e da Terminologia Cultural (DIKI-KIDIRE, 2009). Para a organização e o tratamento do banco de dados, utilizou-se o programa computacional Flex e, para a elaboração do glossário, o software Lexique Pro. O glossário contém, como resultado preliminar, 111 termos, que são apresentados em ordem alfabética, sendo 33 ilustrados. A escolha desse objeto de estudo se justifica pela sua importância cultural e social, que se configura como uma tradição. Espera-se que essa obra terminográfica possa contribuir para o fortalecimento e a preservação dos saberes culturais e linguísticos.
\end{abstract}

PALAVRAS-CHAVE: Socioterminologia; plantas medicinais; Parkatêjê.

ABSTRACT: This paper consists in the study of the medicinal plants methodology, which is used for medicinal treatment and healing of the Parkatêjê diseases, an indigenous community localized in the Mãe Maria Indigenous Land, in Bom Jesus do Tocantins, southeast of Pará. The practical result of this work was the elaboration of a socioterminological glossary of medicinal plants, which emerges from the Pajé's speech; he is considerate a specialist in indigenous health, according to Athias (2015). The study is based on theoretical and methodological presupposes of Socioterminology (FAULSTICH, 1990, 1995, 2006, 2010a e 2010b; GAUDIN, 1993), and Cultural Terminology (DIKI-KIDIRE, 2009). To the organization and treatment of the database, the computational program Flex was used, and for the glossary elaboration, the software Lexique Pro. The glossary contains, as preliminary results, 111 terms, shown in alphabetical order, 33 being illustrated. The choice of this subject was made due to its cultural and social importance.

\footnotetext{
${ }^{1}$ Mestre em Linguística pela Universidade Federal do Pará (UFPA). Doutoranda em Linguística vinculada ao PPGL (Programa de Pós-Graduação em Letras) da Universidade Federal do Pará (UFPA). E-mail: jaqreis108@gmail.com .

${ }^{2}$ Professora Associada IV do Instituto de Letras e Comunicação da Universidade Federal do Pará vinculada à Faculdade de Letras (FALE) e ao PPGL (Programa de Pós-Graduação em Letras). É Bolsista de Produtividade em Pesquisa do CNPq (PQ2). E-mail: mariliaferreira1 @ gmail.com .
} 
Reis e Ferreira - Pajé, conhecimento cultural e terminologia de plantas medicinais em parkatêjê

We expect that this terminographical work might contribute for the fortification and preservation of cultural and linguistic knowledge.

KEYWORDS: Socioterminology; medicinal plants; Parkatêjê.

\section{Comunidade e pajé}

A língua Parkatêjê pertence ao tronco Macro-Jê, do complexo dialetal Timbira, do qual também fazem parte línguas como CanelaKrahô, Canela-Ramkokamekra, Pykobiê, Apinajé, Canela Apaniekra, Krikati. A comunidade Parkatêjê é constituída por aproximadamente 560 indivíduos, dos quais apenas os mais velhos falam fluentemente a língua tradicional. A situação sociolinguística do Parkatêjê é de obsolescência, considerando-se que as crianças já aprendem a língua portuguesa como primeira língua, e o número de falantes ativos da língua indígena diminui a cada óbito. Essa perspectiva nada otimista sobre o Parkatêjê nos levou à elaboração de um glossário dos itens da flora relativo às plantas medicinais usadas pelos indígenas.

Da figura do pajé, pouco se pode enunciar. Sabe-se, com base em narrativas dos próprios indígenas, que a esse especialista, e a suas mãos, era dado um dom de benzedura e alquimia de interações medicamentosas feitas em determinadas plantas, para curar os mais diversos males que apareciam entre os seus. O pajé, ao receber seu dom, passava por testes de coragem e de conhecimento de um mundo encantado e secreto. Apesar de saber que sua vida como pajé seria restrita em inúmeros sentidos, ele aceitava o desafio de conhecer os segredos da floresta. Para a realização da presente pesquisa, tivemos a oportunidade de trabalhar diretamente com o último pajé dos Parkatêjê, o senhor Nãkoti (conhecido como Domingos), que fala a língua tradicional fluentemente.

De acordo com Motta-Maués, o pajé apresenta:

[...] uma espécie de marca, de sinal, que indica e confirma a existência do dom xamanístico, para o bem (no caso dos pajés ou curadores), assim como para o mal (no caso da Matintapereras e dos Lobisomens). No caso do primeiro, esse sinal informa sobre a "escolha" de 
alguém, pelas entidades da pajelança, para intermediar a relação - tida como necessária -, entre as pessoas e o mundo encantante, resolvendo para elas, problemas (males do corpo e da alma; embora, a rigor, um pajé também possa fazer o mal às pessoas (mas essa não é a face marcante de seu perfil) (MOTTA-MAUÉS e VILLACORTA, 2008, p. 23).

Para o pajé, os problemas relacionados à doença "vêm de dentro do corpo e não de fora dele". Tais doenças podem estar relacionadas com espíritos do mal, que se apossam da mente e do corpo de uma pessoa. Quando alguém adoece, isso, para o pajé, é atribuído ao "corpo aberto". Para curar a pessoa, ele "fecha o corpo" com as mãos, fazendo rezas na cabeça e no local da dor referido pelo doente, com a finalidade de expulsar qualquer entidade sobrenatural que esteja enfraquecendo a pessoa. Essa prática realizada pelo pajé se configura como um ritual xamanístico, que, conforme Motta-Maués e Villacorta, trata-se de:

[...] uma área privilegiada do sistema de crenças, essencial no que se refere ao fornecimento de condições que possibilitem aos indivíduos lidar com forças e poderes que não podem controlar, mas que estão presentes e com os quais têm de se defrontar em suas vidas. Além disso, é aquele que fornece os meios indispensáveis para resolver problemas cuja solução para eles não pode ser alcançada de outro modo. Tratase, no caso, das doenças de ordem-natural (que dependem de causas mágicas ou da ação de entidades sobrenaturais), as quais normalmente exigem a intervenção de um pajé (xamã) [...] que na pejelança, destaca-se como elemento chave a figura do "pajé" ou "curador", exatamente o elo de ligação entre as pessoas e o sobrenatural - o "mundo do encantante" - por meio do contato que ele pode manter com as entidades dessa ordem [...] e os espíritos, além das forças mágicas que é capaz de manipular (MOTTA-MAUÉS e VILLACORTA, 2008, p. 331-332).

Atualmente, a Comunidade Indígena Parkatêjê possui dois postos de saúde, um localizado no km 30, na Comunidade Indígena Mãe Maria, e o outro no km 35, na aldeia Rõhôkatêjê, conhecida como Negão. O posto de saúde do $\mathrm{km} 30$ conta com a colaboração de uma técnica de 
enfermagem $k u p \tilde{e}^{3}$, que reside há nove anos na aldeia. Já no posto de saúde do $\mathrm{km} \mathrm{35}$, a técnica de saúde é indígena.

De acordo com a técnica de enfermagem da aldeia Mãe Maria, ocorrem, vez por outra, algumas doenças que podem ser tratadas no posto de saúde, entre elas diarreia, gripe e febre. Além dessas patologias, há a ocorrência de ferimentos provocados por animais peçonhentos. Nesses casos, é inevitável ir à cidade em busca de atendimento médico.

Apesar disso, ainda se pode identificar, na comunidade Parkatêjê, a figura do pajé ou curador, considerado especialista em medicina indígena tradicional, termo com o qual estamos trabalhando. De acordo com Athias ${ }^{4}$, esta é também conhecida como:

[...] medicina indígena, ou simplesmente sistemas de cuidados, sistema de cura, práticas tradicionais de cura ou simplesmente medicina tradicional, diz respeito a uma variedade de terapêuticas, cuidados, tratamentos e práticas de cura, que fazem parte do conhecimento tradicional dos povos indígenas do continente americano, e que ainda são utilizadas por esses povos em suas comunidades na atualidade (ATHIAS, 2015, p. 2).

Conforme o autor, a medicina indígena tradicional é "praticada por distintos especialistas nas áreas indígenas, e que, em geral, são chamados de pajés" (ATHIAS, 2015, p. 2). Tal denominação para designar esses especialistas em cura pode variar de acordo com os grupos indígenas, que os chamam de benzedores, curadores, curandeiros, xamãs, dentre outros. Logo, a presença do pajé na comunidade é vista como uma alternativa de fácil e rápido acesso e de baixo custo para o tratamento e a cura das doenças, que são tratadas com remédios feitos à base de plantas medicinais. Na maioria dos casos, são os índios mais velhos que procuram o pajé ou curador para tratar suas enfermidades, ou simplesmente para receber rezas para "fechar o corpo" contra doenças.

\footnotetext{
${ }^{3}$ Kupẽ: denominação utilizada pelos Parkatêjê para os não índios.

${ }^{4}$ Texto apresentado em uma palestra proferida pelo Prof. Dr.: Renato Athias, no Instituto de Filosofia e Ciências Humanas da Universidade Federal do Pará (IFCH/UFPA), intitulada "Práticas tradicionais de cura e a articulação com os modelos de atenção nos DSEIs", promovida pelo Núcleo de Estudos e pesquisas sobre Etnicidade/Grupo de Estudos sobre Populações Indígenas Eneida Correa de Assis (GEPI-UFPA), realizada em 26 de abril de 2016.
} 
Já os mais jovens preferem o tratamento oferecido pela Biomedicina, medicina oficial ou, ainda, medicina ocidental, concebida como "um conjunto de tratamentos, cuidados, práticas de curas dos nãoíndios, geralmente entendida como dominante ou hegemônica, nos estados nacionais" (ATHIAS, 2015, p. 3). Segundo o autor, ao contrário da medicina ocidental, a medicina indígena se configura como um entendimento próprio oriundo do contexto natural, social, cultural e histórico do povo indígena, que reconhece a importância da participação do pajé nesse sistema de cura e tratamento de doenças.

Atualmente, podemos dizer que a medicina indígena tradicional ainda resiste, apesar da dominância da medicina ocidental. É uma das vias por meio das quais é possível manter os saberes e os conhecimentos adquiridos através das gerações por meio da cultura, da língua e da tradição oral dos povos indígenas, que lutam pela sua sobrevivência. Por tudo isso, torna-se necessário registrar os termos especializados das plantas medicinais que emergem do discurso do pajé à luz das abordagens teórica-metodológicas da Socioterminologia e da Terminologia Cultural. Mas, antes, vamos situar os estudos terminológicos a partir de sua abordagem tradicional.

\section{Teoria Geral da Terminologia: perspectiva tradicional}

Sabe-se que os estudos acerca da Terminologia moderna surgem com Eugen Wüster, engenheiro austríaco considerado "o pai da Terminologia moderna"5 (GAUDIN, 1993, p. 24). Após os estudos apresentados em sua tese, publicou, em 1931, o livro Die Internationale Sprachnormung in der Tecknik, besonders in der Eletronik (FAULSTICH, $2010 a$, p. 4). Nessa obra, suas preocupações com os termos especializados "eram de ordem puramente metodológica e normativa" (FAULSTICH, 1995, p. 1). Para tanto, Wüster propôs unificar as terminologias em uma só, a fim de criar uma norma prescritiva para a conceptualização dos termos. Esse pensamento pode ser evidenciado quando ele diz que:

\footnotetext{
5 "Le père de la terminologie moderne".
} 
A normalização linguística em terminologia supõe a unificação, por seleção, das terminologias já existentes e a criação neológica. Esses aspectos, e, mais concretamente, a evolução dos elementos da língua, geralmente não se incluem na teoria da língua geral. $\mathrm{Na}$ linguagem geral, o que importa é expressar-se com correção, é dizer em conformidade às normas descritivas, levando em conta que cada nível estilístico corresponde uma norma descritiva diferente. Em contraste, a terminologia enfoca a utilidade da linguagem, a qual se manifesta através de normas prescritivas (WÜSTER, 1998, p. 24. Tradução nossa) ${ }^{6}$.

Tal base metodológica tinha como propósito padronizar os conceitos dos termos, considerados distintos do léxico comum. Nesse sentido, para Barros (2004, p. 53), o "princípio que regia tal objetivo era a univocidade entre o conceito e o termo e o termo que o designa (um único termo pode designar um conceito)". Como assinala a autora, o estudioso defendeu a eliminação da ambiguidade na linguagem e propôs a univocidade e universalidade do léxico especializado, considerado dissociado do discurso, ponto de vista que descartou a variação linguística, a polissemia e a sinonímia ou homonímia presentes no contexto de uso da língua.

Por esse prisma, Wüster deu origem à base da Teoria Geral da Terminologia (TGT), que apresenta enfoques cognitivos e normativos, considerados elementos essenciais para o desenvolvimento da área. Para tanto, estabelece os princípios norteadores da TGT, pautados em uma base metodológica assentada na sistematização e na padronização dos conceitos dos termos a fim de ser seguida na produção terminográfica de dicionários terminológicos, cuja estrutura deve ser precisa para garantir uma linguagem adequada nos discursos técnicos e científicos (KRIEGER e FINATTO, 2004).

Para as autoras, o caráter multidisciplinar da Terminologia causa inquietação em muitos pesquisadores, que, devido a essa característica,

\footnotetext{
6 "La normalización linguística en terminología supone a la vez la unificación, por selección, de las terminologías ya existentes, y la creación neológica. Estos dos aspectos, y más concretamente la evaluación de los elementos de la lengua, no suelen incluirse en la teoria de la lengua general. En el linguaje general, lo que importa es expresarse com corrección, es decir, en conformidad a las normas descriptivas, teniendo en cuenta que cada nível estilístico le corresponde una norma descriptiva diferente. En contraste, la terminología se enfoca hacia la utilidad del linguaje, lo cual se manifiesta a través de las normas prescriptiva".
} 
não a consideram uma disciplina independente. Apesar da discussão em torno da autonomia da disciplina, ela apresenta sua própria identidade, assegurada pelo seu objeto de estudo: o termo técnico-científico. Essa relação com a Linguística Aplicada surge pelo fato da Terminologia ir além da Linguística em virtude de reunir vários conhecimentos linguísticos, os quais permitem relacioná-los ao aspecto prático da Linguística Aplicada. Sob essa ótica, Krieger e Finatto esclarecem que:

Pertencer à lingüística aplicada é precisamente o que caracteriza, em larga medida, o estudo científico em geral da Terminologia. Isso torna implícito o fato de que ela é um ramo da Lingüística Aplicada. [...]. Ela vai além da linguística por reunir conhecimentos linguísticos em todos os domínios da vida e de torná-los úteis a todos os domínios da vida (KRIEGER e FINATTO, 2004, p. 21).

Apesar disso, Wüster pontuou a diferença entre as duas áreas por meio de seus objetos de estudo: para a Linguística, a língua de forma geral, e, para a Terminologia, o léxico especializado (termo) considerado como uma:

[...] unidade lexical com um conteúdo específico dentro de um domínio específico. É também chamado de unidade terminológica. O conjunto de termos de uma área especializada chama-se conjunto terminológico ou terminologia (BARROS, 2004, p. 40. Destaques da autora).

Como se pode depreender, a TGT possui uma visão redutora e bastante prescritiva, cujos postulados favorecem a concepção de que os termos são designações que se manifestam no conhecimento científico. Por isso, apresentam características peculiares, com o intuito de contribuir para uma linguagem técnica ideal, que os diferenciam da linguagem geral.

Dessa forma, a TGT tem suscitado várias críticas em virtude de seu caráter prescritivo, pois ficava a cargo dos profissionais de cada área normatizar os termos que deveriam ou não ser usados. Essa ideia é defendida pela TGT, tomando por base a comunicação eficiente atrelada à noção de univocidade e de monovalência do termo. Para Wüster, essas características do termo estão presentes em um contexto de discurso 
específico, que possui apenas um significado, independentemente das situações de comunicação que envolvem o léxico especializado. Tal noção constitui uma representação reducionista do termo, visto, nesse caso, de acordo com Faulstich (2006, p. 27), como uma "forma standard" que serve apenas para denominar conceitos técnicos e científicos.

No entanto, apesar de tantas reflexões em torno da TGT, ela ainda é considerada o marco inicial dos estudos terminológicos. Além disso, apresenta reconhecimento internacional em função da contribuição de Wüster, que estabeleceu os princípios teóricos e aplicados para a produção de obras terminográficas. Essa prática faz com que a TGT se consolide com estatuto de disciplina, com identidade e objetos de estudo próprios, no ramo das ciências do léxico. Para Barros, a Terminografia "pode ser definida como uma prática de elaboração de vocábulos técnicos, científicos e especializados" (BARROS, 2004, p. 68). Essa ciência é considerada a face aplicada da Terminologia, cuja finalidade é a produção de obras terminológicas ou terminográficas, por meio das quais são estabelecidos modelos para a organização da estrutura do dicionário (ou glossário).

Um novo conceito acerca desse ramo é apresentado por Faulstich (1990), que definiu essa área como sendo a prática da Terminologia. Dessa forma, "o trabalho do terminológo prático ou terminógrafo consiste em recolher e organizar os termos e as noções de uma mesma área, sob a forma de léxicos, glossários, dicionários, etc." (FAULSTICH, 1990, p. 207). Para tanto, Faulstich apresenta algumas tipologias de obras terminográficas de que se ocupa a Terminografia, dentre as quais podemos citar:

Dicionário terminológico: dicionário que apresenta a terminologia de um ou de vários domínios;

Glossário: a) repertório que define termos de uma área científica ou técnica, dispostos em ordem alfabética, podendo apresentar ou não remissivas; b) repertório em que os termos, normalmente de uma área, são apresentados em ordem alfabética ou em ordem sistemática seguidos de informação gramatical, definição, remissivas podendo apresentar ou não contexto de ocorrência. Nota: os glossários em ordem alfabética e os em ordem sistemática podem também conter sinonímia, variante(s) e equivalente(s); c) repertório em que os termos são apresentados em 
ordem alfabética ou em ordem sistemática seguidos de informação gramatical e do contexto de ocorrência;

Banco de terminologia: repertório terminológico automatizado, constituído de um conjunto organizado de dados terminológicos (FAULSTICH, 1995, p. 5-7).

Conforme a autora, as obras acima citadas têm diferentes finalidades e particularidades estruturais ao expor o saber terminológico, que variam de acordo com a realidade da pesquisa e os consulentes de cada área de interesse dos estudos terminológicos.

De modo geral, a Terminologia e a Teminografia caracterizam-se como duas áreas distintas, mas que se relacionam quanto ao tratamento dado aos termos especializados. Além disso, a Terminografia estabelece diferentes modelos para o tratamento dos dados, o que permite uma constante renovação para a construção de uma metalinguagem específica para cada metodologia adotada para a elaboração de uma obra terminográfica (BARROS, 2004, p. 68).

Portanto, no bojo dos posicionamentos supracitados acerca da TCT, surgem novas abordagens a partir da Terminologia, as quais se diferenciam pelo objeto de estudo, pela metodologia e pela análise e descrição dos termos. Além disso, essas vertentes procuram entender os termos especializados de acordo com seu funcionamento e dinamicidade em contextos reais de uso. Dentre essas, estão os postulados teóricos e metodológicos da Socioterminologia e da Terminologia Cultural, cujos fundamentos são adotados para este trabalho.

Socioterminologia e Terminologia Cultural: interface social e cultural do termo especializado

Com um direcionamento inovador em prol de uma nova visão acerca do uso e do funcionamento das terminologias na interação social, divergindo das limitações da TGT, surge a Socioterminologia, que "nasce como uma nova corrente, depois que Jean-Claude Boulanger declara, em 1991, no seu artigo Une lecture sócio-culturelle de la terminologie, que a perspectiva socioterminológica" (FAULSTICH, 2006, p. 29) "vem atenuar os efeitos prescritivos exagerados de algumas proposições normativas" 
(BOULANGER, 1991, p. 25 apud FAULSTICH, 2006, p. 29). Como bem explica a pesquisadora, essa disciplina se preocupa em apresentar uma proposta voltada para a descrição dos termos em sua dimensão interativa e discursiva, tendo em vista que estes não podem ser dissociados do contexto social e linguístico.

O estudo acerca da Socioterminologia surge na França com François Gaudin e sua tese de doutorado, intitulada Pour une socioterminologie: des problèmes sémantiques aux pratiques institutionelles, publicada em dezembro de 1993 (FAULSTICH, 2006, p. 29). De acordo com Faulstich (2006), nesse trabalho, Gaudin discute com mais propriedade os aspectos da realização dos termos no "âmbito das práticas linguísticas e sociais concretas dos homens que empregam tais termos" (FAULSTICH, 2006, p. 29), quando declara que "[...] a Socioterminologia, com o suposto de que deseja ultrapassar os limites de uma terminologia 'de escrivão'"7 (GAUDIN, 1993, p. 216), deve situar essa corrente "no âmbito das práticas linguísticas e sociais concretas dos homens que empregam tais termos" (FAULSTICH, 2006, p. 29). Como bem explica a pesquisadora, essa disciplina se preocupa em apresentar uma proposta voltada para a descrição dos termos em sua dimensão interativa e discursiva, tendo em vista que o mesmo não pode ser dissociado do contexto social e linguístico. Nesse sentido, a Socioterminologia:

[...] é um ramo da terminologia que se propõe a refinar o conhecimento dos discursos especializados, científicos e técnicos, a auxiliar na planificação linguística e a oferecer recursos sobre circunstâncias da elaboração desses discursos ao explorar as ligações entre a terminologia e a sociedade (FAULSTICH, 2006, p. 29).

Segundo a autora, a Socioterminologia se ocupa da investigação da variação linguística dos termos presentes no meio social, levando em conta todas as manifestações de uso que uma comunidade faz dos termos. Assim sendo, Faulstich postula que:

[...] a terminologia está voltada para observação do uso do termo em contexto de língua oral e de língua escrita,

\footnotetext{
7 “[...] la socioterminologie, pour peu qu'elle veuille dèpasser les limites d'une terminologie 'greffière' $[\ldots] "$.
} 
atitude que implica a possibilidade de identificação de variantes dentro de um mesmo contexto ou em diferentes contextos em que o termo é usado (FAULSTICH, 2006, p. 30).

Para tanto, Faulstich propõe uma base teórico-metodológica para a Socioterminologia, construída ao longo de seus estudos, inspirada nos princípios da Etnografia,

[...] cuja linha de conduta deriva de um postulado fundamental, que é a existência de uma ordem: o engajamento entre as pessoas, a interação de uns com os outros. Assim, as atitudes interacionais precisam ser observadas e analisadas nos mais diferentes espaços e em diferentes níveis (FAULSTICH, 2010a, p. 16-17).

Outra influência é da Sociolinguística, pois, de acordo com Faulstich, "o conceito de variação linguística, desenvolvido pelas vias da Sociolinguística, serve de suporte para essa nova interpretação que vem se desenvolvendo sobre variação terminológica" (FAULSTICH, 2010a, p. 15). Apesar disso, a pesquisadora esclarece que a "Socioterminologia não é, de fato, uma disciplina derivada da Sociolinguística, porém não podemos negar que é a visão mais flexível da sociedade e da comunidade que conduz os especialistas a esse novo percurso" (FAULSTICH, 2010a, p. 15). Tal área de estudo é considerada um ramo da Linguística, que privilegia os aspectos sociais do léxico de especialidade, assim como da Sociolinguística, que também apresenta a preocupação com os aspectos social e variacionista presentes no uso da língua.

Como toda ciência, a Socioterminologia se dedica ao estudo da análise do funcionamento dos termos que circulam na comunicação especializada. Dessa forma, configura-se como uma disciplina descritiva sob uma abordagem linguística, pois observa a realização dos termos nas situações reais de uso na interação social. Daí seu objeto de estudo ser o termo, também conhecido como unidade terminológica (UT), doravante entendido como signo linguístico dotado de significado que pode variar conforme o contexto de uso.

A Socioterminologia tem como objetivo sistematizar as variações terminológicas de acordo com a natureza linguística que os termos apresentam. Por isso, ela é considerada, no campo dos estudos 
terminológicos, um método de pesquisa, além de ser uma disciplina descritiva. Partindo dessa concepção, em 1995 Faulstich (2006) organiza uma subárea dessa corrente, sob duas vertentes: a primeira consiste na Socioterminologia como prática do trabalho terminológico, cujo fundamento, em relação às análises, está relacionado às condições de circulação do termo no funcionamento da linguagem. No que se refere à segunda, esta considera a Socioterminologia como uma disciplina descritiva, cuja finalidade está voltada para a perspectiva linguística na interação social em que os termos se apresentam.

A organização proposta pela autora é importante para a produção de uma obra terminográfica, sobretudo quando esse produto considera as variações em seu contexto de uso social e cultural. Em vista disso, podemos dizer que os estudos da linguagem desenvolvidos pela Socioterminologia compartilham o princípio de conceber o aspecto social e as variantes terminológicas que compõem a natureza linguística da linguagem de especialidade. Então, não é demasiado dizer que tal disciplina ultrapassa as barreiras tradicionais apresentadas pela TGT em relação ao termo e avança em direção a um estudo funcional e descritivo do léxico especializado, levando em consideração o universo discursivo em que ele emerge.

\section{Terminologia Cultural}

Seguindo a vertente dos termos especializados sob o enfoque cultural, surge a Teminologia Cultural, doravante TC, proposta por DikiKidire (2009). Tal campo de estudo mantém uma interrelação com a Socioterminologia, tendo em vista o interesse pela relação entre a interação comunicativa, a sociedade e a cultura que se apresenta nos léxicos especializados. A Terminologia Cultural (TC), nome atribuído por Diki-Kidire (2009), é considerada um campo de estudos terminológicos bastante recente; em função disso, as referências não são muitas, além de serem pouco detalhadas (ARAGÃO, 2010). A Terminologia Cultural proposta pelo autor é uma área voltada para o estudo da descrição e análise dos termos realizados no contexto cultural. 
Desse modo, o contexto da diversidade cultural do termo é o foco principal dessa abordagem teórica (ARAGÃO, 2010), que leva em consideração "a apreensão da realidade, os modos de viver, pensar e sentir das comunidades que são representados nos termos por elas utilizados e está determinado pela percepção cultural de cada povo" (ARAGÃO, 2010, p. 42). A partir disso, Diki-Kidire (2009) considera que

[...] a cultura é um conjunto das experiências vividas, nas produções realizadas pelos conhecimentos gerados por uma comunidade humana que vive em um mesmo espaço em uma mesma época. Isto significa que existe, por uma parte, uma diversidade cultural tanto no espaço como no tempo, por outra parte, a uma grande expressão da cultura que permite as diversas experiências e os diversos conhecimentos sedimentares nos arquivos da memória coletiva (DIKI-KIDIRE, 2009, p. 2. Tradução nossa) ${ }^{8}$.

De acordo com o autor, isso significa que existe uma grande diversidade cultural cujas raízes surgem através das experiências e dos conhecimentos adquiridos e acumulados ao longo da história de cada povo. Tal aprendizado é arquivado na memória coletiva de cada pessoa e, por isso, é repassado de geração em geração. Daí a necessidade de se considerar o uso dos termos em um contexto específico de uso, tendo em vista que a cultura é um ponto de confluência entre sociedade e língua, cuja relação se configura como a identidade cultural e linguística de um povo. Isso permite que todos os membros de uma comunidade possam interagir a partir da criação dos termos que circulam em determinada cultura, favorecendo, dessa forma, o surgimento de uma comunicação que pode se manifestar de várias maneiras: por meio de gestos, palavras, comportamentos e atitudes.

Na Terminologia Cultural, os termos ganham uma dimensão social, sobretudo, através da cultura, considerada o pilar dessa abordagem. Nessa vertente, a cultura é entendida a partir de várias dimensões que compreendem o comportamento do homem, tanto em âmbito social,

\footnotetext{
8 “"...] la cultura es el conjunto de las experiencias vividas, de las producciones realizadas y de los conocimientos generados por una comunidad humana que vive en un mismo espacio yen una misma época. Esto significa que existe, por una parte, una diversidad de culturas tanto em el espacio como em el tiempo $\mathrm{y}$, por otra parte, hay um grosor de la cultura que permite a las diversas experiencias y diversos conocimientos sedimentars e en los archivos de la memoria colectiva".
} 
quanto individual, por meio da apropriação de seus conhecimentos e saberes, cuja compreensão gera termos específicos, que se integram à cultura e geram variedades linguísticas, sinonímias, homonímias e polissemias nos léxicos especializados.

Ao contrário da TGT, que se preocupava em padronizar os termos em nível internacional devido ao fato de considerá-los como um objeto estanque, a TC valoriza os saberes cuja apropriação favorece a criação de representações simbólicas geradas a partir dos conhecimentos, considerados "arquivos" adquiridos na relação entre homem e sociedade durante a sua existência. Conforme reitera Diki-Kidire,

[...] estes arquivos representam tantas referências simbólicas comuns a partir das quais os membros de uma mesma comunidade cultural podem entender quando se comunicam entre si. Obviamente, as palavras, os gestos, os comportamentos, as situações, tudo se interpreta de forma mais adequada e se entende com mais facilidade quando a gente comporta as mesmas referências simbólicas (DIKI-KIDIRE, 2009, p. 2. Tradução nossa) ${ }^{9}$.

Tais conhecimentos, conforme a TC, constituem a história, os costumes e a tradição de um povo - como é o caso estudado no presente artigo. A tradição dos Parkatêjê certamente apresenta termos especializados, produzidos por meio dos conhecimentos culturais e sociais do pajé, sobretudo na prática de uso das plantas medicinais.

\section{Procedimentos metodológicos}

Para nortear a metodologia deste trabalho, adotamos os postulados teóricos da Socioterminologia cunhados por Faulstich (1990, 1995, 2006, 2010a e 2010b) e Gaudin (1993). Seguindo tais orientações, a metodologia apresenta as seguintes etapas, que foram adaptadas de acordo com as especificidades da pesquisa.

\footnotetext{
9 “[...] estos archivos representan tantas referencias simbólicas comunes a partir de las cuales los membros de una misma comunidad cultural pueden entenderse cuando comunican entre ellos. Obviamente, las palabras, los gestos, los comportamientos, las situaciones, todo se interpreta de forma más adecuada y se entende con más facilidad cuando la gente comparte las mismas referencias simbólicas".
} 
A pesquisa, para fazer o levantamento, a descrição e a análise da terminologia das plantas medicinais usadas pelos Parkatêjê, precisava ser desenvolvida com os índios, considerados especialistas nessa tradição. Para isso, realizamos o trabalho de campo na aldeia Parkatêjê do km 30. $\mathrm{Na}$ ocasião, foram entrevistados alguns índios, que nos indicaram os colaboradores para a pesquisa. Dessa forma, nosso principal colaborador foi o pajé, ou curador. Os dados que permitiram a realização deste trabalho foram coletados em quatro viagens de campo. A primeira viagem ocorreu no mês de setembro de 2015 , e as demais, nos meses de janeiro, março e junho de 2016.

De acordo com os índios entrevistados, o pajé é, atualmente, o único detentor de conhecimentos específicos acerca da flora com propriedades medicinais. Ainda segundo relatos dos colaboradores, somente o pajé pode preparar, administrar e prescrever os remédios produzidos à base de plantas medicinais aos índios de sua comunidade, sendo, por isso, considerado um especialista em medicina tradicional Parkatêjê. Devido a esse dom, ele conhece variados termos especializados referentes a essa prática cultural. Além do pajé, mais nove colaboradores foram arrolados para participar do trabalho, sendo quatro homens com idades entre 45 e 90 anos e cinco mulheres entre 36 e 56 anos. Desses, oito são índios Parkatêjê nascidos e criados na aldeia, portanto falam fluentemente a língua tradicional, além do português.

Durante o andamento da pesquisa de campo, observamos que, nessa comunidade, os índios não apresentam o hábito de cultivar as plantas medicinais em canteiros ou hortas: o pajé planta algumas espécies na mata, e a maioria delas é extraída de seu habitat natural, a floresta nativa da reserva Parkatêjê, a qual possui uma infinidade de espécies de plantas medicinais. Para utilizar tais plantas, o especialista em saúde indígena adentra a mata e colhe as espécies de que precisa para fazer os remédios. Em seguida, parte das plantas é retirada para fazer o medicamento de acordo com as propriedades medicamentosas, as indicações terapêuticas e o modo de preparo e de uso, que devem respeitar as variadas técnicas de coleta e manejo.

Com a finalidade de entender com mais clareza as citadas etapas da prática tradicional de uso das plantas medicinais utilizadas pelo pajé, produzimos uma "Árvore de domínio", que é "um diagrama hierárquico 
composto por termo-chave de uma especialidade, semelhante a um organograma" (KRIEGER e FINATTO, 2004, p. 134). Essa produção nos possibilitou compreender cada domínio que compõe o universo das plantas medicinais. Tal construção foi realizada a partir das observações feitas durante as entrevistas com o especialista em saúde, por meio das quais podemos entender os procedimentos utilizados por ele na extração e identificação das espécies de plantas.

A partir disso, delimitamos o campo semântico: as plantas medicinais, objeto da presente investigação, que comporão o termoentrada do glossário, bem como a seleção de outras informações relevantes para a geração da obra terminográfica. Dessa forma, a partir do campo semântico principal, outros campos foram constituídos, para melhor compreensão das ações e dos saberes do pajé que envolvem o processo de feitura dos remédios. São eles: a parte da planta utilizada, o modo de preparo e de uso e as indicações terapêuticas, todos ilustrados na Árvore de domínio (figura 1) a seguir:

Imagem 1: Árvore de domínio 1

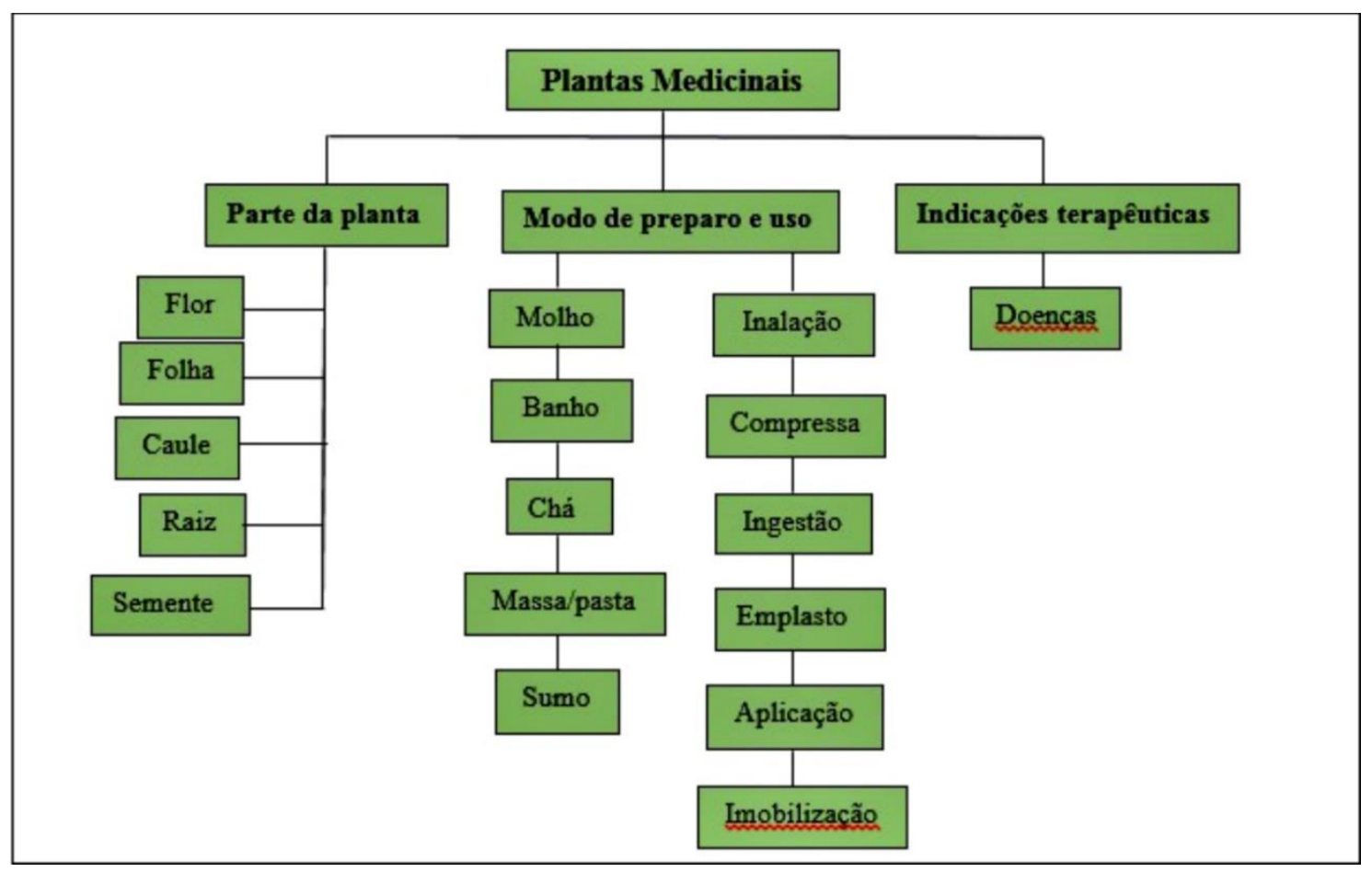

Fonte: Elaborada pela autora (2015). 
Conforme podemos ver nessa Árvore de domínio, elaborada a partir das entrevistas com o pajé, buscamos apresentar a organização dos procedimentos realizados por ele durante a coleta das partes das plantas medicinais, que devem ser especificadas de acordo com cada tipo de remédio e doença. Dessa maneira, ele utiliza a flor, a folha, o caule (retira a casca, o espinho, o óleo, o lodo e o palmito), a raiz (batata), a semente (caroço) e o cipó das espécies de plantas para produzir diversos tipos de medicações, tais como chá, banho, sumo, pasta, xarope, garrafada, pastas, entre outros. Esses recursos de preparação de medicamentos também são conhecidos entre os Parkatêjê como "remédio do mato".

As informações elencadas na Árvore de domínio nortearam a elaboração de uma Ficha Terminológica, doravante FT, que "funciona como uma certidão de nascimento" (FAULSTICH 1995, p. 4), tendo em vista que as informações obtidas por meio da FT irão formar a estrutura interna de uma obra terminográfica. Para tanto, tem por finalidade a coleta e o registro de dados do objeto de estudo dessa pesquisa. Segundo Krieger e Finatto, a ficha terminológica:

[...] pode ser definida como um registro completo e organizado de informações referentes a um dado termo, segmentos de texto, onde esse termo ocorre, seus contextos de uso, informações sobre variantes denominativas, sinônimos, construções recorrentes que o acompanham. (KRIEGER e FINATTO, 2004, p. 136).

A FT é importante para a coleta, organização e seleção dos dados que formarão os verbetes terminológicos de um dicionário ou glossário, haja vista que se configura como um elemento que nos possibilita extrair todas as informações pertinentes ao termo especializado em estudo. Cabe frisar que as fichas terminológicas podem variar de acordo com o contexto da pesquisa, uma vez que cada trabalho apresenta suas especificidades. Para tanto, Krieger e Finatto esclarecem que cada trabalho:

[...] pode exigir um tipo distinto de ficha terminológica que, em linhas gerais, alimentará tipos diferentes de verbetes e de dicionários. Desse modo, não se pode imaginar que haja um modelo único de ficha que pudesse 
atender a todas as especificidades dos diferentes trabalhos (KRIEGER e FINATTO, 2004, p. 136).

À vista disso, a FT adotada para esta pesquisa foi elaborada e adaptada a fim de atender as necessidades metodológicas específicas deste trabalho. Dessa maneira, levamos em consideração a realidade cultural, social e linguística em que os termos especializados das plantas medicinais são produzidos, isto é, nos discursos particularizados do pajé em contexto real de uso. A FT elaborada compreende as seguintes informações: nome da planta na língua Parkatêjê e em português, indicações terapêuticas, parte da planta usada, modo de preparo e de uso, contraindicação, exemplos e notas antropológicas. As informações extraídas da FT revelam um número significativo de termos especializados presentes na língua Parkatêjê referentes às plantas medicinais.

Além da ficha terminológica, produzimos um questionário semiestruturado contendo 93 perguntas a fim de serem aplicadas, posteriormente, por meio de entrevistas, tanto ao pajé quanto aos demais colaboradores da pesquisa. O questionário contém perguntas relevantes para a pesquisa relativas à cultura, ao costume, à tradição, à cosmologia e a relatos de experiência de uso dos remédios feitos à base de plantas medicinais, bem como de cura e tratamento de doenças.

Para a organização e o tratamento do banco de dados, utilizamos o recurso de duas ferramentas de programas computacionais, a saber: o Flex10 (Fieldworks Language Explore versão 8.2.8) e o Lexique Pro'11 (versão 3.5 ), os quais nos possibilitaram fazer tal procedimento. $O$ programa Flex foi o primeiro utilizado e nos permitiu organizar todos os dados coletados em arquivos cuja base foi alimentada por meio de informações referentes ao léxico especializado das plantas medicinais, bem como de imagens dessa flora.

\footnotetext{
${ }^{10}$ O FLE $x$ é um programa de distribuição gratuita produzido pela International Society of Linguistics (antes conhecida como Summer Institute of Linguistics). O programa FLEx pode ser baixado pelo link: http://fieldworks.sil.org/download/fw-828/ .

${ }^{11}$ O Lexique Pro é um software desenvolvido pelo SIL (Summer Institute of Linguistics) que permite editar, exibir e distribuir dados lexicais de línguas naturais. É usado para criar bases de dados, gerenciar arquivos e gerar documentos em formato de dicionário para Word ou para Web, conforme a escolha do pesquisador (MARTINS e LIMA, 2014). O programa Lexique Pro pode ser baixado gratuitamente pelo site: www.lexiquepro.com/download.
} 
Esse recurso foi muito importante para a constituição e o tratamento dos dados, pois nos viabilizou gerar os termos-entradas, oriundos do campo semântico das plantas medicinais, além de possibilitar a inserção de outros campos específicos do universo da pesquisa, tais como: o nome na língua indígena, o nome popular, o nome científico, as indicações terapêuticas, a parte da planta usada, o modo de preparo e de uso, exemplos e notas antropológicas, conforme demonstram as Figuras 2 e 3.

Figura 1: Amostra do banco de dados dos termos especializados das plantas medicinais

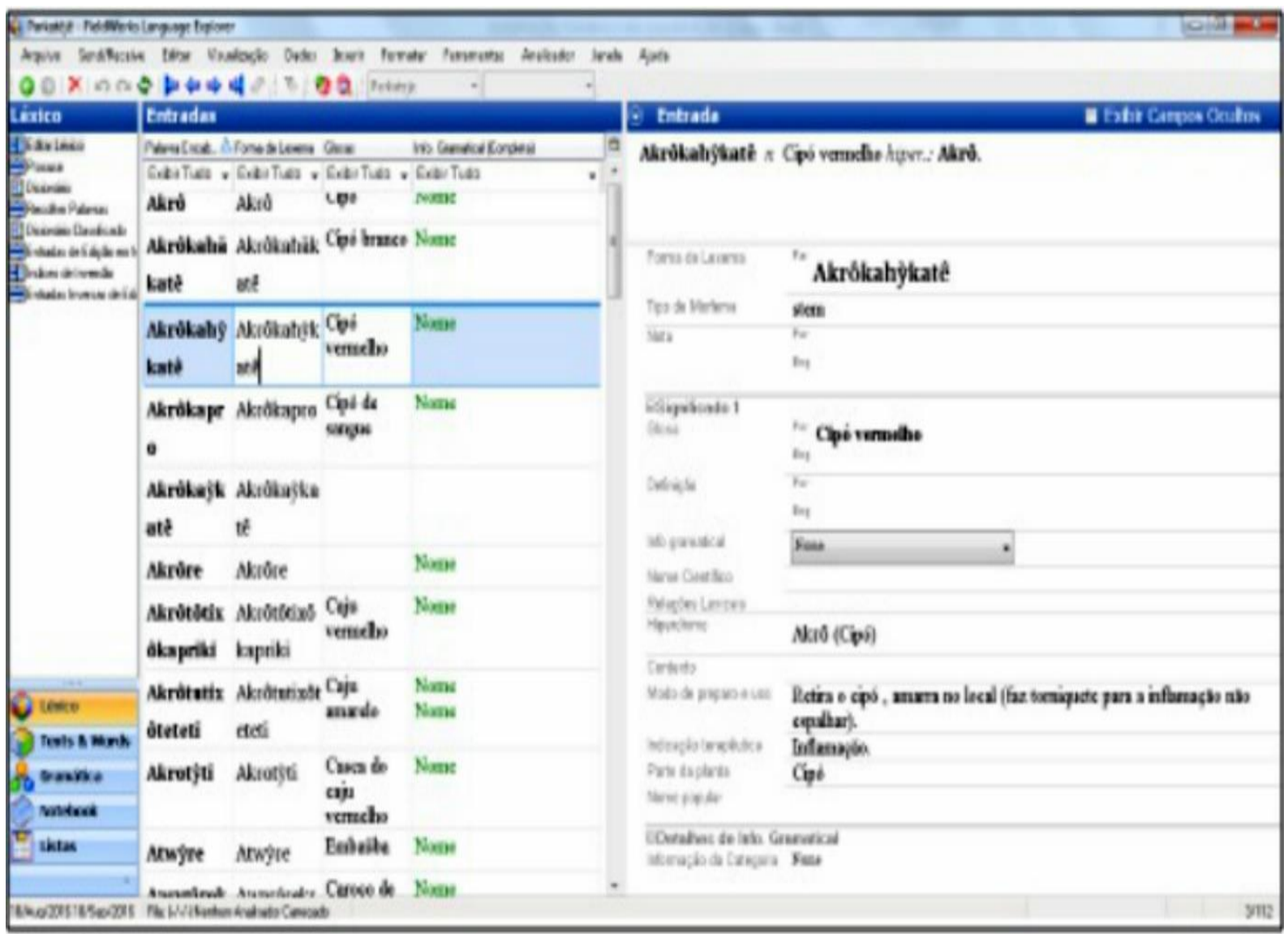

Fonte: Programa Flex (2016).

De acordo com as figuras 2 e 3, podemos observar os termos especializados que indicam as entradas em língua Parkatêjê, bem como as traduções em português e a classe gramatical à qual o léxico especializado pertence. Além dessas informações, verificamos outros 
Reis e Ferreira - Pajé, conhecimento cultural e terminologia de plantas medicinais em parkatêjê

campos referentes aos termos especializados, tais como a nota antropológica e a ilustração.

Figura 2: Amostra do banco de dados dos termos especializados das plantas medicinais

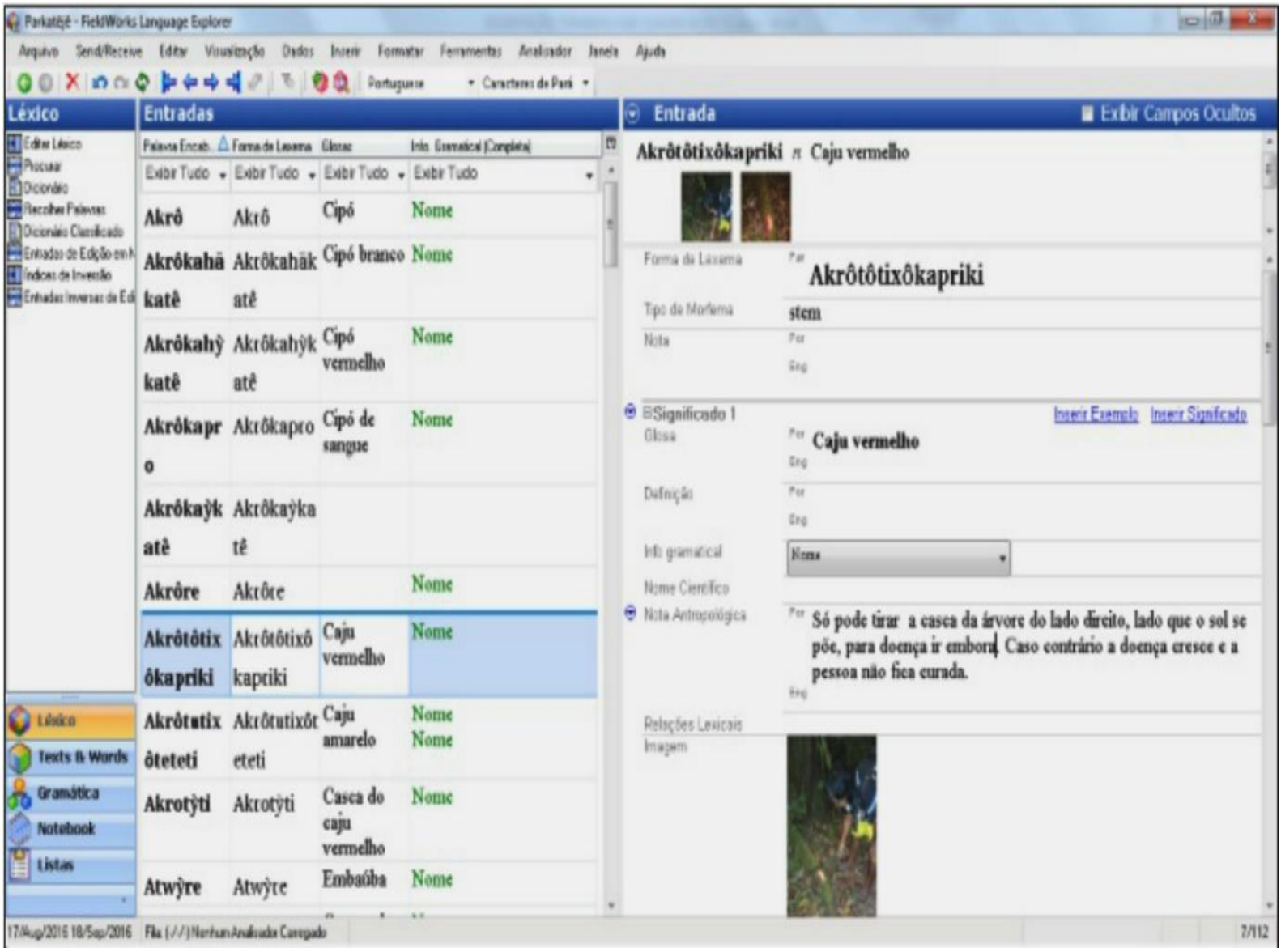

Fonte: Programa Flex (2016).

O segundo programa utilizado foi o Lexique Pro, que nos permitiu gerar o glossário da terminologia das plantas medicinais em Parkatêjê. Esse software se constitui como uma importante ferramenta, cujos recursos nos possibilitam editar, exibir e distribuir dados tanto do léxico geral quanto do léxico especializado. Além disso, proporciona a organização e elaboração da macro e da microestrutura do glossário, cujas estruturas seguiram as orientações metodológicas propostas por Faulstich (2010a). Tal programa apresenta, entre outras, a função de elaborar obras terminográficas em forma de dicionários e glossários 
digitais e impressos. A Figura 4 mostra o termo-entrada e os outros campos do glossário.

Figura 3: Representação do termo entrada principal do glossário

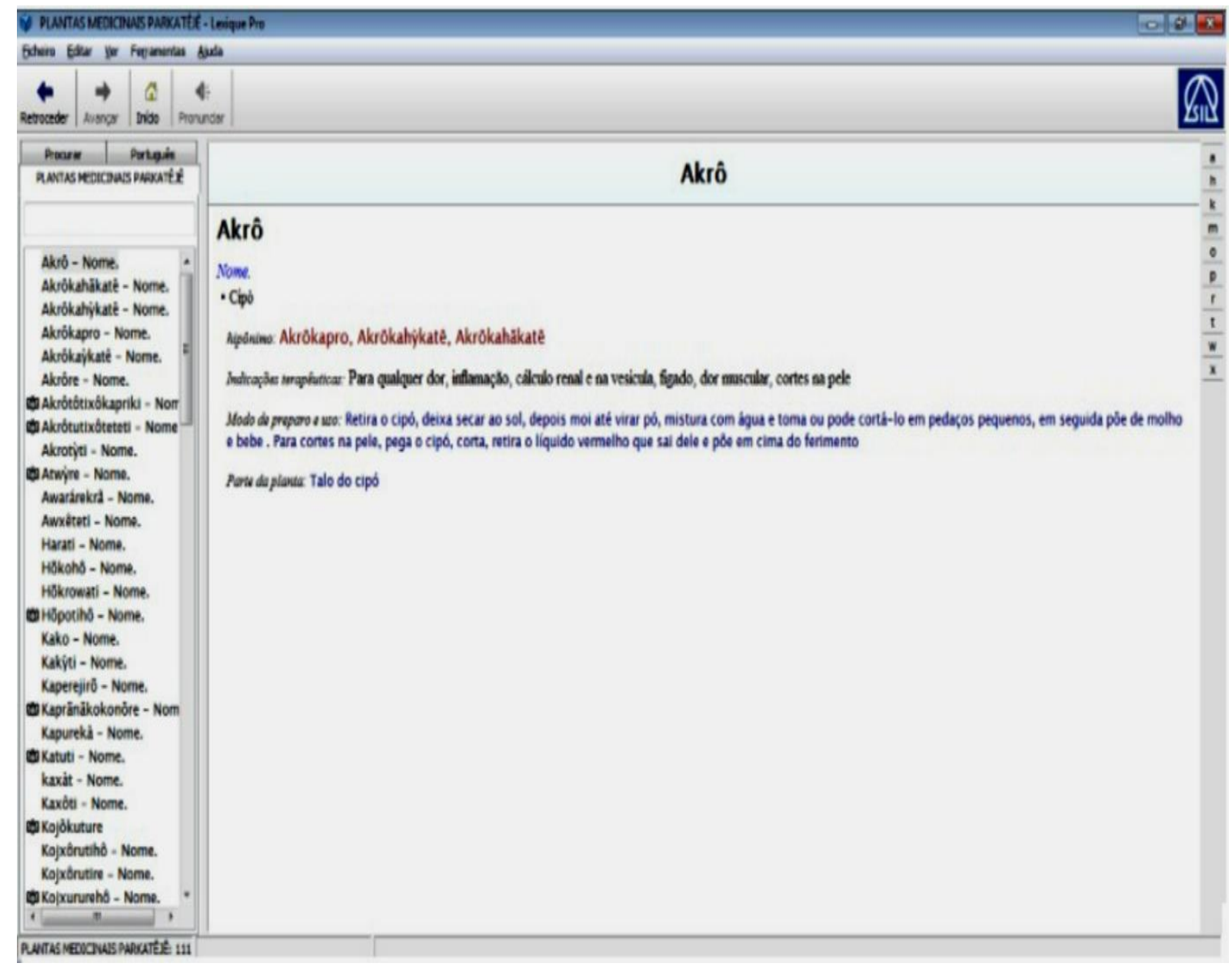

Fonte: Programa Lexique Pro (2016).

Neste trabalho, optamos por fazer a organização e o tratamento dos dados no FLEx em virtude de tal programa se adequar às necessidades e peculiaridades da pesquisa. Após alimentar o banco de dados, foi possível exportá-los para o Lexique Pro, que originou a forma final do glossário da terminologia das plantas medicinais. A escolha desse material se deve à necessidade de registrar e documentar os dados da pesquisa para a produção de um futuro material didático que possa ser aproveitado tanto no âmbito da saúde quanto no da educação indígena Parkatêjê. 


\section{Produção do glossário: características e organização interna}

O glossário da terminologia das plantas medicinais é uma obra terminográfica semibilíngue que apresenta uma estrutura constituída por uma macroestrutura, responsável pela organização das entradas dos verbetes no glossário, e de uma microestrutura, que diz respeito à descrição dos repertórios. Dessa forma, Faulstich define o glossário como:

[...] um conjunto de termos, normalmente de uma área, apresentados em ordem sistêmica ou em ordem alfabética, seguidos de informação gramatical, definição, remissivas, podendo apresentar ou não contexto de ocorrência do termo (FAULSTICH, 2010b, p. 178).

A referida autora pontua a distinção entre um dicionário de terminologia e um glossário, que, segundo ela, consiste sobretudo na "quantidade de termos que um ou outro contém, de acordo com as finalidades de informações do conhecimento terminológico a serem repassados e em conformidade com o público alvo" (FAULSTICH, 2010b, p. 178). Já o dicionário:

[...] apresenta a terminologia de uma ou de várias áreas científicas e/ou técnicas, disposta em ordem sistemática ou em ordem alfabética. Um dicionário que apresente a terminologia de uma só área comporta um alto grau de exaustividade. (FAULSTICH, 2010a, p. 58).

Logo, de acordo com Faulstich (2010a), o que diferencia um dicionário terminológico de um glossário é justamente a quantidade de termos que cada um apresenta. O dicionário compila uma grande quantidade de termos, ao passo que um glossário lista uma quantidade menor (cerca de 200 termos).

A organização da macroestrutura do presente glossário apresenta fácil identificação, leitura e compreensão dos termos especializados pelos consulentes da obra, tendo em vista que o público-alvo está voltado principalmente para a comunidade indígena, além da científica e da 
acadêmica. Por isso, optamos por uma linguagem simples, que pode ser acessível a todos. Assim sendo, a macroestrutura foi elaborada para atender às necessidades e particularidades da pesquisa.

Na macroestrutura do glossário, os verbetes estão apresentados em ordem alfabética, conforme propõe Faulstich (2010a), organizados conforme o nome da planta medicinal em Parkatêjê e escritos de acordo com a ortografia da língua proposta por Araújo (2016). Além disso, alguns termos serão acompanhados por ilustrações, quando possível. O significado de cada termo em português aparecerá ao lado do termo principal, mas sem seguir a ordem alfabética.

A microestrutura representa a parte mais importante de uma obra terminográfica, pois indica a organização dos dados dentro do verbete. Devido a isso, apresenta-se flexível, a fim de atender às necessidades e especificidades da pesquisa. Essa maleabilidade possibilita aos consulentes da obra uma fácil compreensão no momento da leitura. Com esse propósito, Faulstich (2010b) indica um modelo de microestrutura elaborado para servir de base para a elaboração de glossários e dicionários. O modelo a seguir passou por algumas adaptações:

Entrada + Campo semântico + Categoria gramatical + Definição + Contexto de uso e fonte \pm Variante \pm Remissiva \pm Nota \pm Ilustrações.

Com base nesse modelo, elaborarmos a organização da microestrutura dos verbetes do glossário ora proposto. Para tanto, tivemos que acrescentar mais campos, a fim de fazer adaptações de acordo com a necessidade da pesquisa. Assim sendo, apresentamos a microestrutura adotada para a composição do presente glossário:

Entrada +12 Categoria gramatical + Nome português+Definição \pm
Remissiva \pm Sinônimo \pm Nota antropológica + Exemplo + Tradução +
Nome científico + Indicações terapêuticas + Modo de preparo e uso
+ Nome popular \pm Nota + Parte da Planta \pm Ilustrações.

${ }^{12}$ Os campos marcados com "+" são de preenchimento obrigatório. Se, no decorrer da pesquisa, os dados referentes a esses campos forem encontrados, deverão ser preenchidos; caso contrário, ficarão em branco (FAULSTICH, 2010a). 


\section{Amostra do glossário da terminologia das plantas medicinais}

O glossário da terminologia das plantas Medicinais em Parkatêjê é uma obra terminográfica que apresenta 111 termos, considerados entradas principais, dos quais 33 foram ilustrados e estão distribuídos em ordem alfabética de acordo com o campo semântico referente ao objeto da pesquisa. Como ilustração, apresentamos um modelo de um verbete do glossário (Figura 4) contendo a terminologia da planta medicinal Akrôtôtixôteteti ("caju amarelo"). Nesse exemplo, as setas indicam as principais informações dos verbetes e o modo como eles se encontram organizados na microestrutura do glossário. Em seguida, há outra ilustração (Figura 5), referente a uma página da obra.

Figura 4: Ilustração das informações do termo entrada do glossário

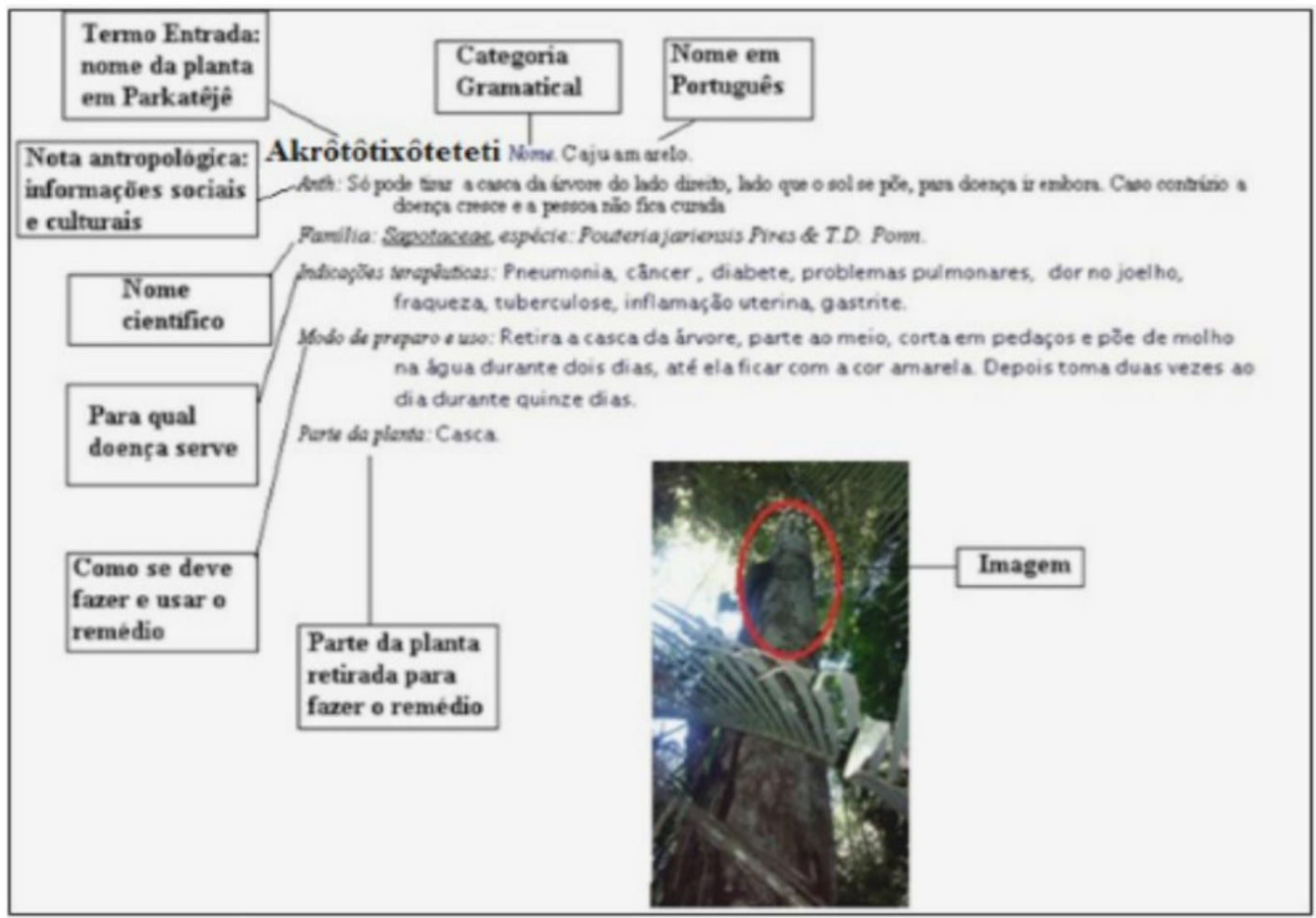

Fonte: Elaborada pela autora (2016). 
Reis e Ferreira - Pajé, conhecimento cultural e terminologia de plantas medicinais em parkatêjê

Figura 5: Amostra do glossário dos termos especializados das plantas medicinais Parkatêjê

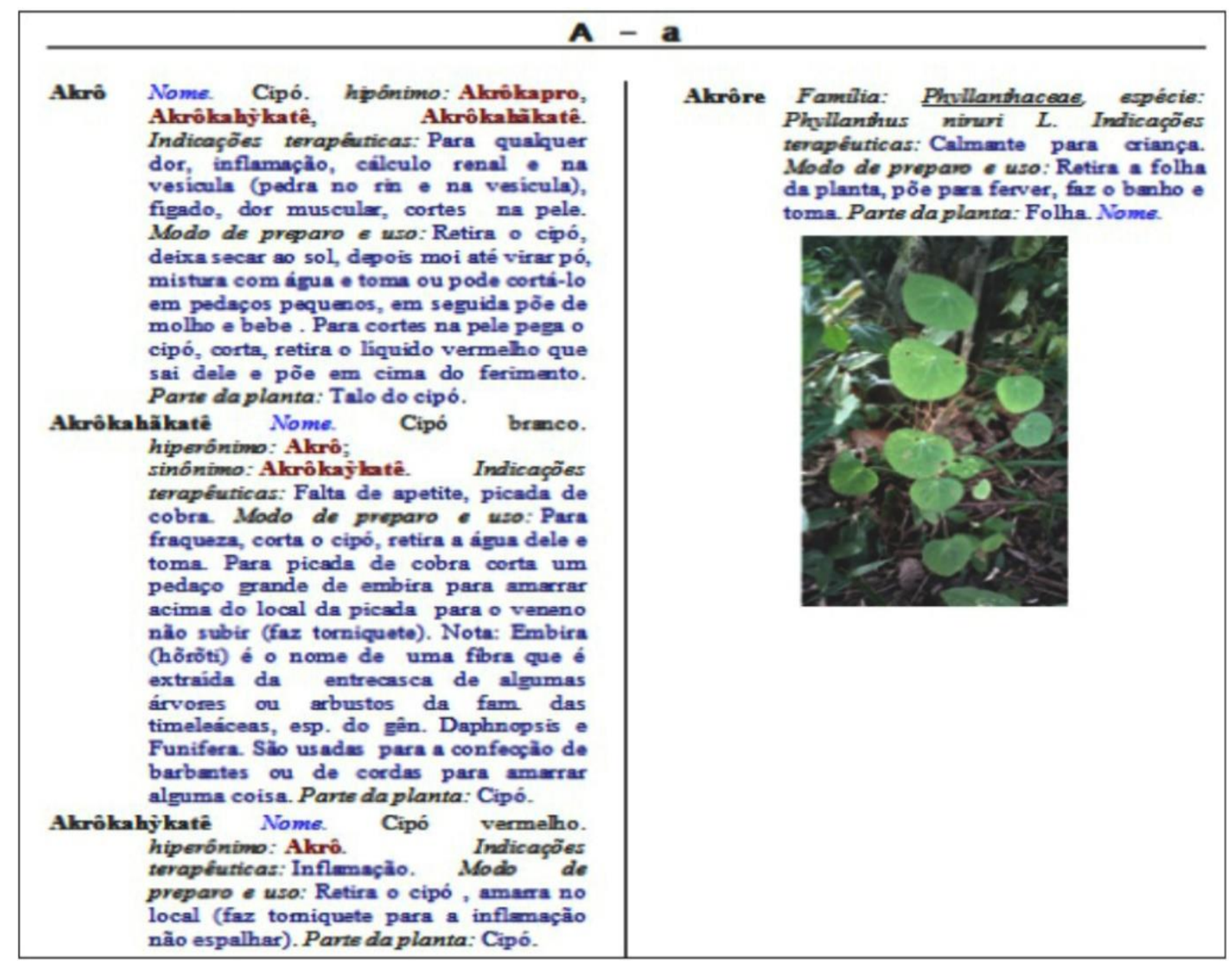

Fonte: Elaborada pela autora (2016).

\section{Considerações finais}

O presente trabalho focalizou a produção do glossário da terminologia das plantas medicinais utilizadas para o tratamento e a cura de doenças pelos Parkatêjê. Tal estudo foi desenvolvido visando a Dissertação de Mestrado, realizada no campo da Terminologia, situada na área da Linguística e com interface na vertente social da Socioterminologia e na perspectiva da Terminologia Cultural. A partir dessa pesquisa, confeccionamos um glossário dos termos especializados 
das plantas medicinais contendo 111 entradas, organizadas em ordem alfabética, sendo 33 ilustradas.

A pesquisa, que possibilitou a produção do glossário da terminologia das plantas medicinais Parkatêjê, revelou um resultado que apresenta um repertório repleto de termos especializados, com significados relacionados aos aspectos sociais e culturais dessa língua. Tais termos emergem do discurso do pajé, especialista em saúde indígena, que, por meio do seu dom e de seu saber, produz remédios feitos à base de plantas. Além disso, os léxicos especializados oriundos desse trabalho foram analisados, descritos e documentados com o intuito de contribuir para o fortalecimento e a manutenção da língua e da cultura Parkatêjê.

Esse tipo de glossário se difere de outros, de línguas cuja situação não é a de obsolescência. Certamente, poder contar com outros falantes hábeis no uso da sua língua materna faz muita diferença. De todo modo, acreditamos que os resultados do trabalho em tela poderão contribuir para salvaguarda de dados como os que foram descritos aqui.

\section{Referências bibliográficas}

ARAGÃO, M. S. S. A Socioterminologia e Etnoterminologia das plantas medicinais no Nordeste. Periódicos da Universidade Federal da Paraíba, v. 15, n. 1, 2010.

ARAÚJO, L. M. S. Parkatêjê x Português: Caminhos de resistência. IX Congresso Internacional da "Brazilian Studies Association”. New Orleans: Tulane University, 2008.

Dicionário Parkatêjê-Português. Belém: Edição da autora, 2016.

Estruturas subjacentes de alguns tipos de frases declarativas afirmativas do dialeto gavião-jê. 1977. Dissertação (Mestrado em Linguística) - Florianópolis, Universidade Federal de Santa Catarina (UFSC), [1977].

Conhecendo nosso povo: comunidade Indígena Parkatêjê. Brasília: Ministério da Educação e Desportos; Belém: Secretaria de Estado de Educação, 1997.

BARROS, L. A. Curso básico de Terminologia. São Paulo: Edusp, 2004.

DIKE-KIDIRE, M. Um enfoque cultural de la terminología. Debate Terminológico, $\mathrm{n}$. $5,2009$. 
FAULSTICH, E. Metodologia para projeto terminográfico. In: Simpósio Latinoamericano de Terminologia, 2. Encontro brasileiro de terminologia técnico-científica, 1. Anais. Brasília- DF, 1990.

Socioterminologia: mais que um método de pesquisa, uma disciplina. Ciência da Informação, Brasília, v. 24, n. 3, p. 281-298, 1995.

Variantes terminológicas: princípios linguísticos de análise e método de recolha. In: Actes réflexions méthodologiques sur le travail en terminologie et en terminotique dans les langue latines. Nice: Université de Nice Sophiea-Antipolis, 1996.

Entre sincronia e diacronia: variação terminológica no código e na língua. In: Actas da VI Riterm. Havana, 1998.

A socioterminologia na comunicação científica e técnica. Ciência e Cultura, v. 58, n .2, São Paulo, 2006.

Brasília, 2010a.

Socioterminologia: termo e variação. Brasília: Universidade Federal de

Para gostar de ler um dicionário. In: RAMOS, C. de M. de A; BEZERRA, J. de R. M.; ROCHA, M. de F. S. (Org.). Pelos caminhos da Dialetologia e da Sociolinguística: entrelaçando saberes e vidas. São Luís: UFMA, 2010b. v. 1. p. 166185.

FERREIRA, M. N. O. Estudo Morfossintático da língua Parkatêjêe. 2003. Tese (Doutorado em Linguística) - Campinas: UNICAMP, [2003].

Contato entre línguas, perda linguística e identidade étnica: notas sobre o povo Parkatêjê. Caderno de Letras da UFF, Rio de Janeiro, n. 40, 2010.

Construções nominais classificatórias em Parkatêjê. Estudo da língua(gem), Vitória-Campinas, v. 9, n. 1, 2011.

FINATTO, M. J. B. O papel da definição de termos técnico-científicos. Revista da Associação Brasileira de Linguística, Curitiba, v. 1, n. 1, 2002.

GAUDIN, F. Pour une sócio-terminologie: des problèmes sémantiques aux pratiques institutionnelles. Rouen: Publications de l'Université de Rouen, 1993.

Bruxelas: Duculot, 2003.

JÕPAIPARE, Toprãmre Krôhôkrenhữm. Me ikwỳ tekjê ri: isto pertence ao meu povo. Marabá, PA: Gknoronha, 2011. 
KRIEGER, M. G; FINATTO, M. J. B. Introdução à Terminologia: teoria \& prática. São Paulo: Contexto, 2004.

LAVELEYE, D. Distribuição e heterogeneidade no complexo cultural da "pajelança". In: MAUÉS. R. H; VILLACORTA, G.M. Pajelança e religiões africanas na Amazônia. Belém: EDUFPA.

LIMA, A. F. Socioterminologia da indústria madeireira. Tese (Doutorado). Fortaleza: Universidade Federal do Ceará, 2010.

LISBOA. P. L. B. (Org.). Caxiuanã: paraíso ainda preservado. Belém: Museu Paraense Emílio Goeldi, 2013.

MARTINS, A. F. C. Terminologia da indústria do alumínio. Dissertação (Mestrado). Belém: Universidade Federal do Pará, 2007.

MARTINS, A.F.C; LIMA, A.F. Utilização do programa Lexique Pro na Elaboração de Dlossário e dicionários Eletrônicos. In: RAZKY, A; LIMA, A.F; OLIVEIRA, M.B; COSTA, E (Org.). Estudos Sociodialetais no Português Brasileiro. Campinas: Pontes Editores, 2014. v. 1. p. 257-277

MELLO, G. B. R. Sistema de crenças e terapêuticas complementares: um desafio para as políticas de saúde indígena. In: XXVII Congresso de la Asociación Latino americana de Sociología, VIII Jornada, Buenos Aires, 2009.

MOTTA-MAUÉS, M. A. VILLACORTA, G. M. Matintapereras e pajés: gênero, corpo e cura na pajelança amazônica In: ___ (Org.). Pajelança e religiões africanas na Amazônia. Belém-Pará: EDUFPA, 2008. p. 327-346.

RODRIGUES, A. D. Línguas brasileiras: para o conhecimento das línguas indígenas. São Paulo: Edições Loyola, 1986.

WÜSTER, E. Introducción a la teoría general de la terminología y la lexicografía terminológica. Barcelona: Universitat Pompeu Fabra, 1998.

Recebido em: 22/12/2016 * Aprovado em: 21/09/2017 * Publicado em: 31/12/2017 